\title{
THE
}

\section{Understanding the genetics of asthma and implications for clinical practice}

Jennifer R. Mammen

University of Rhode Island, jmammen@uri.edu

Kimberly Arcoleo

Follow this and additional works at: https://digitalcommons.uri.edu/nursing_facpubs

The University of Rhode Island Faculty have made this article openly available.

Please let us know how Open Access to this research benefits you.

This is a pre-publication author manuscript of the final, published article.

Terms of Use

This article is made available under the terms and conditions applicable towards Open Access Policy Articles, as set forth in our Terms of Use.

\section{Citation/Publisher Attribution}

Mammen, JR., Arcoleo, K. (2019) Understanding the genetics of asthma and implications for clinical practice. Journal of the American Association of Nurse Practitioners: July 2019 - Volume 31 - Issue 7 - $p$ 384-387. doi: 10.1097/JXX.0000000000000246 
Understanding the genetics of asthma and implications for clinical practice

Authors: Jennifer R. Mammen, PhD, NP-BC ${ }^{1,2}$; Kimberly Arcoleo, PhD, $\mathrm{MPH}^{2}$

1. University of Rhode Island, College of Nursing, Kingston RI

2. University of Rochester School of Nursing, Rochester, NY

Key words: Asthma, genetics, genomics, phenotype

Corresponding Author: Jennifer Mammen

jmammen@uri.edu

University of Rhode Island College of Nursing,

350 Eddy Street, Providence RI

\section{Word Counts}

Title:

Number of references:

Number of tables: 1

Number of figures: 0

Word count abstract: 180

Word count paper: 1539 


\begin{abstract}
Asthma is one of the most common heritable diseases globally, with highly variable clinical expression and response to treatment that is attributed to underlying genetic differences. Hundreds of loci on multiple chromosomes are associated with asthma. Genetic testing is not currently recommended for management, however, recognition of common asthma phenotypes, which are the result of genetic and environmental interactions, can help to guide treatment decisions. Asthma phenotypes are divided into two major categories of atopic and non-atopic disease, with further subdivisions within in each category that are associated with patterns in clinical presentation and responsiveness to treatment. In general, earlier onset, and allergic disease will respond well to traditional therapy with inhaled corticosteroids and leukotrienes, as these medications target corresponding inflammatory pathways for allergic disease. However, patients with late onset, symptom predominant (lacking inflammation) and obese asthma may be resistant to standard therapy and may require treatment modification. These patients are at risk for overuse of inhaled corticosteroids with poor response, and may benefit more by use of long acting beta agonists, long acting muscarinic agonists, weight reduction, and exercise. Research into genetic testing for responsiveness to common asthma medications is early stage, but shows evidence of clinically utility and cost effectiveness.
\end{abstract}


Asthma is one of the most common chronic health conditions world-wide, affecting approximately $8.3 \%$ of U.S adults and children ${ }^{1}$. Like many common conditions, it tends to run in families, and individuals with a family history of asthma are four to six-times more likely to develop disease, with estimates of heritability ranging from 25 to $95 \%{ }^{2}$. Albeit a common diagnosis, asthma is now recognized as a highly heterogenous syndrome that can present differently from person to person. This variation in individual expression is attributed to a complex interplay of genetic and environmental factors, which are currently only partially understood $^{2}$. Socioeconomic and environmental influences have been long recognized as significant factors and targeted for intervention. However emerging evidence suggests that genetic determinants are equally important in the expression and progression of disease, and research in this area is rapidly gaining focus.

Two primary approaches have been used to identify genes related to development of asthma: linkage studies and genome wide association studies (GWAS). Linkage studies examine family members with and without asthma and look for significant patterns in their DNA that correspond to clinical expression of disease. GWAS, on the other hand, are large-scale population studies that do not rely on families, in which researchers sequence the entire DNA of individuals with disease and compare to ethnically-matched individuals without disease to determine if specific genetic patterns or variants are associated with phenotypes or traits. Evidence from these studies suggests that asthma has a multifocal, mixed dominance inheritance pattern (both recessive and autosomal dominant), involving over 100 individual loci on each chromosome and more than 20 independent chromosomal regions (consisting of millions of bases) ${ }^{2,3}$. However, research is early stage in these areas, and the precise role of individual genes in expression of asthma remains ambiguous. 
The broad scope for genetic variability helps to explain the marked diversity seen in clinical practice. When a disease is caused by a consistent or small group of genes (genetic homogeneity) there is generally greater uniformity in disease expression and therapeutic response. Because asthma is caused by hundreds of susceptibility genes interacting differently with each other and the environment, there is potential for substantial heterogeneity in expression of disease and response to treatment. In fact, it is estimated that genetic factors may not only account for differences in disease severity, but also for up to $70 \%$ of variability in response to inhaled corticosteroids and $92 \%$ of variability in response to short acting beta agonists ${ }^{4,5}$. One such example is Indacaterol, a newer long acting beta agonist currently approved for treatment of $\mathrm{COPD} /$ chronic bronchitis, which is occasionally used in the treatment of severe asthma. Indacaterol is metabolized by through the UGT1A1 pathway, which is encoded by a gene complex located on chromosome two ${ }^{6}$. Genetic variation at this loci has been found to result in reduced or absent UGT1A1 activity, with subsequently altered medication metabolism and marginally higher serum levels at steady state, which may be related to variable response to this medication ${ }^{7}$. Similarly, multiple gene segments have been identified in relationship to inhaled corticosteroid (ICS) metabolism, and preliminary evidence suggests that genetic testing for steroid responsiveness may ultimately prove to be both cost and clinically effective ${ }^{8}$. Presently, these tests are not available for mainstream use. However, as the field of pharmacogenetics continues to develop, it is likely that genetic testing will play a greater role in clinical management, as it might be used to predict how patients will respond to treatment and guide future treatment approaches. A list of known medication-genetic interactions with potential biomarkers is available at the Food and Drug Administration website, and includes long acting beta agonists (LABA) such as Aformoterol and Formoterol ${ }^{9}$. 
At present, genetic testing is not routinely indicated, and treatment is more usefully guided by asthma phenotype. Phenotypes are the observable characteristics of disease that result from interactions of genes and environment-i.e. how the patient presents clinically and responds to therapy. There are some exceptions to this rule, and patients with poor response to treatment or suspicion of other asthma look-alikes, such as bronchiectasis, ciliary dyskinesia, or alpha I anti-tripsin disorder, warrant specialty referral and may require further testing ${ }^{10}$. In most circumstances, however, asthma phenotypes can be recognized based on observable characteristics, such as allergic versus non-allergic disease, responsiveness to inhaled steroids, age of onset (pediatric versus adult onset), and comorbid obesity ${ }^{11}$.

Albeit having similar symptoms (e.g. chest tightness, wheeze, cough), the precipitating pathology and corresponding approaches to treatment differ by phenotype. While there is no universal consensus, there appear to be approximately five to seven distinct groups, depending on source ${ }^{11}$. These have been broadly classified into two primary groups: atopic (eosinophilic) and non-atopic (non-eosinophilic) asthma, also commonly referred to as allergic/non-allergic or intrinsic/extrinsic asthma ${ }^{5}$. In this paper we adhere to "atopic" which infers that the host has a genetic tendency to produce eosinophils and $\operatorname{IgE}$ antibiodies in response to antigens which are surface markers found on the surface of allergens.

Atopic asthma phenotypes are now recognized to be further subdivided into early onset (mild, moderate, and severe), late onset (usually severe), and inflammation predominant, the latter of which presents with fewer symptoms but is associated with mixed eosinophilic and neutrophilic inflammation and heightened pulmonary remodeling ${ }^{11}$. Details on similarities and differences between phenotypes are presented in Table 1. Non-atopic asthma phenotypes include late onset obese and symptom predominant asthma, which notable for high levels of symptoms 
but without eosinophilic inflammation. Atopic obese asthma is also clinically distinct from nonatopic obese asthma and can be distinguished by early age of symptom onset with evidence of allergic inflammation ${ }^{12}$. Other sources further categorize phenotypic variations based on precipitating factors, such as trigger-induced, infection-related, and Asprin-induced respiratory disease, however these have not been tied to variable treatment responses and may be less relevant clinically ${ }^{13}$.

While knowing specifically which genotype precede each phenotype is not necessary, ability to identify phenotypes is useful, as responsiveness to treatment does varies between the phenotypes listed in Table $1^{13}$. Specifically, the majority of control medications used to treat asthma, such as inhaled corticosteroids (ICS), leukotriene receptor antagonists (LTRA), and more recently anti-IgE monoclonal antibody therapy, work by inhibiting allergic inflammatory pathways, and are thus not as effective for non-atopic asthma.

Allergic inflammation is mediated by the adaptive immune system via IgE antibodies, $\mathrm{T}$ helper cells, and eosinophils. IgE-mediated inflammation has rapid onset following allergen exposure and may be associated with severe or anaphylactic reactions. In this situation, $\operatorname{IgE}$ antibiodies recognize antigens (markers) on the surface of an allergen, such as pet dander. This triggers IgE to bind to pro-inflammatory immune cells (mast cells) which trigger release of $\mathrm{T}$ helper type 2 cells (Th2) and histamine, the latter of which is cytotoxic and causes immediate inflammation. Eosinophils, the other hallmark of allergic asthma, are triggered by the release interluekins from the Th2 cells ${ }^{10}$. This causes further inflammation and increased bronchial hyperresponsiveness. Thus, atopic asthma is commonly referred to as eosinophilic asthma, and when severe, Th2 type asthma. Mainstay asthma medications such as ICS and LTRA specifically target Th2 mediated cytokines, and block the allergic pathways at multiple levels, 
thereby preventing inflammation and symptoms of asthma. Similarly, anti-IgE biotherapy blocks free serum IgE and prevents initiation of mast cells, histamine and Th2 cells, again inhibiting the allergic inflammatory pathway.

In contrast to atopic asthma, late onset obese asthma and symptom predominant asthma phenotypes lack inflammatory pathology via the adaptive immune system and instead trigger symptoms via T helper type 17 (Th17) pathways, which release an entirely different group of pro-inflammatory mediators (including neutrophils) that can directly cause bronchial hyperreactivity with or without inflammation ${ }^{10}$. It is critical to note that cytokines produced by Th17 are not responsive to steroids. Patients with obese and symptom predominant asthma phenotypes will therefore respond poorly to traditional treatment with ICS and LTRA, and are at risk for overuse of ICS with minimal benefit ${ }^{11}$. Furthermore, in individuals with obese asthma, mechanical limitations on respiration (i.e. chest wall adipose tissue) can induce further bronchial hyperresponsiveness and trigger symptoms without underlying inflammation ${ }^{12}$. Thus, individuals with non-allergic asthma may require a different approach to treatment, and may derived greater benefit from use of long-acting muscarinic agonists (LAMA) or long acting betaagonists (LABA), both of which induce smooth muscle relaxation and alleviate symptoms by targeting bronchospasm rather than inflammation ${ }^{12}$. It is also important to recognize that there may be overlap between phenotypes, with varying degrees of expression of Th2 and Th17 pathways, which further contributes to heterogeneity of response to treatment and the complexity of clinical management.

In conclusion, asthma is no longer considered a single disease entity, but is now viewed as a syndrome comprising multiple phenotypic variations. While genetic testing is not currently indicated, these variants present clinically with different observable characteristics and responses 
to treatment that are based upon underlying genetic differences and interactions of genes with environmental factors. Future clinical management of asthma is likely to be increasingly guided by pharmacogenetics and tailored treatments that target phenotypes specifically. Clinicians should be aware of current phenotype classifications, monitor for expected responses to treatment, adjust medication therapy accordingly, and refer to specialist care when expected outcomes are not achieved. 
1. CDC. Summary health statistics, National Health Interview Survey, 2015. 2015. (Accessed Web Page, 2017, at https://ftp.cdc.gov/pub/Health_Statistics/NCHS/NHIS/SHS/2015 SHS Table_C-1.pdf.) 2. Bijanzadeh M, Mahesh PA, Ramachandra NB. An understanding of the genetic basis of asthma. An understanding of the genetic basis of asthma 2011;134:149-61.

3. Mathias RA. Introduction to Genetics and Genomics in Asthma: Genetics of Asthma. In: A. B, ed. Heterogeneity in Asthma Advances in Experimental Medicine and Biology. Boston, MA: Humana Press; 2014.

4. Keskin O, Farzan N, Birben E, et al. Genetic associations of the response to inhaled corticosteroids in asthma: a systematic review. Genetic associations of the response to inhaled corticosteroids in asthma: a systematic review 2019;9:2.

5. Hernandez-Pacheco N, Pino-Yanes M, Flores C. Genomic Predictors of Asthma Phenotypes and Treatment Response. Genomic Predictors of Asthma Phenotypes and Treatment Response 2019;7:6.

6. Mayo Clinic. at https://www.mayocliniclabs.com/testcatalog/Clinical+and+Interpretive/65428.)

7. Arcapta. Highlights of prescribing information; Arcapta Neohaler. 2017. at https://www.arcapta.com/Arcapta-Prescribing-Information.pdf.)

8. Wu AC, Gay C, Rett MD, Stout N, Weiss ST, Fuhlbrigge AL. Pharmacogenomic test that predicts response to inhaled corticosteroids in adults with asthma likely to be cost-saving. Pharmacogenomic test that predicts response to inhaled corticosteroids in adults with asthma likely to be cost-saving 2015;16:591-600.

9. FDA. at https://www.fda.gov/drugs/scienceresearch/ucm572698.htm.)

10. Lambrecht BN, Hammad H. The immunology of asthma. The immunology of asthma 2015;16:45-56.

11. Hirose M, Horiguchi T. Asthma phenotypes. Asthma phenotypes 2017;18:189-94.

12. Pradeepan S, Garrison G, Dixon AE. Obesity in asthma: approaches to treatment. Obesity in asthma: approaches to treatment 2013;13:434-42.

13. Lockey RF. Asthma phenotypes: an approach to the diagnosis and treatment of asthma. Asthma phenotypes: an approach to the diagnosis and treatment of asthma 2014;2:682-5. 
Table 1. Asthma phenotypes and clinical features

\begin{tabular}{|c|c|c|c|c|}
\hline Phenotype & Symptoms & Pathology & Clinical features & $\begin{array}{c}\text { First line Clinical } \\
\text { Management }\end{array}$ \\
\hline $\begin{array}{l}\text { Inflammation } \\
\text { predominant }\end{array}$ & Low & $\begin{array}{l}\text { Th2, Th17: Mixed } \\
\text { eosinophilic and } \\
\text { neutrophilic } \\
\text { inflammation } \\
\end{array}$ & $\begin{array}{l}\text { Low symptom levels } \\
\text { High sputum eosinophilia, } \\
\text { Elevated FeNO }\end{array}$ & $\begin{array}{l}\text { Higher dose ICS + LTRA } \\
\text { +/- LABA } \\
\text { +/- Anti-IgE }\end{array}$ \\
\hline $\begin{array}{l}\text { Early Onset } \\
\text { Atopic (mild) }\end{array}$ & Low & Th2: Eosinophilic & $\begin{array}{l}\text { Atopic } \\
\text { High symptom levels } \\
\text { High sputum eosinophilia } \\
\text { Elevated FeNO }\end{array}$ & $\begin{array}{l}\text { Low to medium dose ICS } \\
\text { or LTRA } \\
\text { +/- LABA }\end{array}$ \\
\hline $\begin{array}{l}\text { Early Onset } \\
\text { Atopic } \\
\text { (severe) }\end{array}$ & $\begin{array}{c}\text { High with } \\
\text { exacerbations }\end{array}$ & Th2: Eosinophilic & $\begin{array}{l}\text { Atopic } \\
\text { High symptom levels } \\
\text { High sputum eosinophilia } \\
\text { Elevated FeNO }\end{array}$ & $\begin{array}{l}\text { Higher dose ICS } \\
+/- \text { LABA } \\
\text { Consider adding LTRA } \\
\text { Anti-IgE if not controlled }\end{array}$ \\
\hline $\begin{array}{l}\text { Late Onset } \\
\text { Atopic } \\
\text { (Severe) }\end{array}$ & Very high & Th2: Eosinophilic & $\begin{array}{l}\text { Atopic } \\
\text { High symptom levels } \\
\text { High sputum eosinophilia } \\
\text { Elevated FeNO } \\
\text { Not fully reversible with SABA }\end{array}$ & $\begin{array}{l}\text { Higher dose ICS } \\
+/- \text { LABA } \\
\text { Consider adding LTRA } \\
\text { Anti-IgE if not controlled }\end{array}$ \\
\hline $\begin{array}{l}\text { Early } \\
\text { Symptom } \\
\text { Predominant }\end{array}$ & Very high & Non-eosinophilic & $\begin{array}{l}\text { Normal eosinophils counts } \\
\text { Normal FeNO, } \\
\text { May have COPD overlap }\end{array}$ & $\begin{array}{l}\text { Poor response to ICS } \\
\text { Consider: LABA/LAMA }\end{array}$ \\
\hline $\begin{array}{l}\text { Late Onset } \\
\text { Obese }\end{array}$ & High & Non-eosinophilic & $\begin{array}{l}\text { Normal eosinophils counts } \\
\text { Normal FeNO } \\
\text { Decreased pulmonary function } \\
\text { due to weight } \\
\text { Average BMI = } 33\end{array}$ & $\begin{array}{l}\text { Poor response to ICS } \\
\text { Weight loss } \\
\text { Consider: LABA/LAMA }\end{array}$ \\
\hline
\end{tabular}

Notes: BMI=Body mass index; FeNO=Nitric oxide; ICS=Inhaled corticosteroid; LABA= Long acting beta agonist; LAMA=Long acting muscarinic agonist; LTRA=Leukotriene receptor antagonist; SABA=Short acting beta agonist; Th2=T helper type 2 cell; Th17=T helper type 17 cell 